\title{
A Case Study on Quality Management and Digital Innovation
}

\author{
Relationship and Learning Aspects
}

\section{Introduction}

This paper deals with quality management and digital innovation and their interrelationship. There are many definitions of quality management and one way to view the concept is that of Dahlgaard et al. (1998), who see quality management as "a corporate culture characterized by increased customer satisfaction through continuous improvement, in which all employees in the firm actively participate”. Innovation refers to an outcome perceived as new, regardless of whether it is an idea, object or process, as well as to the process of creating this newness (see e.g. Slappendel 1996). In order for the new idea to be an innovation, it must be integrated in meaningful ways into existing social settings (Tuomi, 2006). Digital innovation refers to the use of information and communication technology as a driving force for innovation that has an impact on the structure, processes and organizational landscape (Yoo et al., 2010).

Most organizations have approaches for working with quality management and digital innovation. These approaches are often dealt with in two different functions within an organization, and communication and the establishment of common goals between them are troublesome. However, the task of these two functions is to contribute improved products and services for the customers of the organizations and to improve efficiency. Previous research has shown that poor performance of digital innovation is a serious inhibitor to good business performance and that high efficiency and effectiveness in digital innovation is associated with high organizational performance (Carlson and McNurlin, 1992). In a similar vein, studies have shown that an effective implementation of quality management yields improved business performance (Hendricks and Singhal, 1995, 1996, 1997, 2001a, b; Flynn et al., 1995; Eriksson and Hansson, 2002).

Studies of the relationship between quality management and digital innovation have concentrated on measurements in quality (Myers et al., 1997), and using SERVQUAL and focusing on effectiveness aspects (Van Dyke et al., 1999). Measuring effectiveness is not enough, however. One must also understand how the application of quality management and digital innovation relates. Management needs to determine what values or principles should guide the organization in relation to customers, competitors and suppliers (Dean and Bowen, 1994). All development work is dependent on many factors, for example commitment among co-workers, leadership, the ability to understand customer needs and so forth. Therefore, also the success of digital innovation can be understood and analyzed with the use of principles that describe what characterize successful organizations; i.e. principles of quality management. In specific, digital innovation is strongly connected to processes (Swanson, 1994), improvements, and internal and external customers (Yoo et al., 2010), which are also seen as the core in quality management, see for example Bergman and Klefsjö (2010).

Often one can recognize a frustration among IT professionals that the organization does not understand what they actually need in terms of different solutions, that the implementation of digital innovations is cumbersome and that leadership is invisible in the digital innovation process. Similarly, quality managers are also often frustrated and argue that the management 
team does not understand what is needed in terms of development and that the changes that they stress as important are not prioritized or fully grasped by the organization.

Quality management and digital innovation are dealt with separately, not only during practical work at organizations. In academia, digital innovation and quality management are two independent disciplines, and the exchange of ideas and reciprocal ability to learn from the other discipline are fragmented and limited. The purpose of this paper is to explore the maturity of quality management and digital innovation in an organization. Furthermore, the purpose is to analyse the relationship between and learning opportunities of the two concepts based on that maturity.

The study is conducted at the Swedish Transport Administration and uses a document study and interviews. The data are first presented as a description of how the principles are dealt with in the work with quality management and digital innovation. Secondly, the maturity of these principles for quality management and digital innovation is presented. Thirdly, a comparison between the two concepts is made that is based on the maturity. Lastly, and as a result of this, implications for quality management and digital innovation are discussed.

\section{Framing the research}

\section{Quality management}

Quality management is a concept characterized by its principles, practices and techniques (Dean and Bowen, 1994). The principles are a set of underlying assumptions about how to view the organization and its relation to customers, competitors and suppliers. The practices are viewed as the activities performed to display and embody the principles, such as collecting customer information and conducting customer surveys. The techniques are seen as the guidelines and infrastructure for performing certain practices, such as voice of the customer tables and quality function deployment (Dean and Bowen, 1994).

Schein (1992) discusses organizational culture and how it relates to organizational values. He is of the opinion that there are three levels of culture, where "level" refers to the degree to which the cultural phenomenon is visible to the observer, within an organization. These levels are artefacts, espoused values and basic underlying assumptions. Artefacts are visible organizational structure and processes, which are hard to decipher. Espoused values are strategies, goals and philosophies, and the basic underlying assumptions are unconscious, taken-for-granted beliefs, perceptions, thoughts and feelings. Furthermore, Schein (1992) notes that espoused values are a set of values that become embodied in an ideology or organizational philosophy and thus can serve as a guide and as a way of dealing with issues in an organization. In this paper, the principles are seen as what Schein (1992) notes as espoused values. It is also worth noting cultures can differ within an organization. Morgan (1997) and Hatch (2000) acknowledge the existence of different sub-cultures within the same organization. Hatch (2000) claims that the sub-cultures can be classified on the basis of whether they support, deny or exist in parallel with the general culture's central values. Hence, it is likely that, for example, the IT professionals working with digital innovation and the professionals working with quality management exist in two different sets of sub-cultures where principles have been adopted differently.

In alignment with the view that the application of quality management can change, Lascelles and Dale (1991) identified six levels of adoption of quality management. These levels are "uncommitted", "drifters", "tool pushers", "improvers", "award winners" and "world class". The authors argue that these levels are not necessarily the stages through which organizations 
pass on their quality management journey. They are rather characteristics and behaviors that organizations display in reaction to quality management. Dale and Smith (1997) further developed the maturity model with a grid that includes root causes of problems, issues being faced, typical organizational behaviors and effective transitional action, in order to diagnose the stage of development at the organization. They also suggested some changes in the original levels to instead include 1) "unaware", 2) "uncommitted", 3) “initiators", 4) “drifters”, 5) “improvers”, 6) “award winners” and 7) "world class”.

According to Dean and Bowen (1994), quality management is based on three principles: customer focus, continuous improvement and teamwork. Other advocates of the quality movement include more principles in their conceptualization of quality management (see Bergman and Klefsjö, 2010; Dahlgaard et al., 1998). Bergman and Klefsjö (2010) include six principles of quality management: (1) focus on customers; (2) focus on processes; (3) base decisions on facts; (4) improve continuously; (5) let everybody be committed; and (6) top management commitment. A management system based on the ISO standard should focus on eight principles: (1) customer focus; (2) leadership; (3) involvement of people; (4) process approach; (5) system approach to management; (6) continual improvement; (7) factual approach to decision making; and (8) mutually beneficial supplier relationships (ISO, 2000). As ISO is an international standard and the world's most common business standard (ISO, 2011), this study is based on the ISO principles.

All organizations can have more or less systematic, integrated and proactive approaches to deal with the principles. Previous research shows that some principles may be more appropriate than others depending on whether the organization produces services or goods. For example, process orientation and employee management have been shown to be more appropriate for service organizations (Rönnbäck and Witell, 2008). This illuminates the importance of making suitable conscious choices when deploying principles. Some research denotes the principles that an organization chooses to deploy and their patterns of performance as the organization's ‘quality profile' (Johansson et al., 2010; Rönnbäck et al., 2011). Dahlgaard et al. (1994) describe the quality profile as an average for the whole organization, in which strengths and weaknesses of the various aspects of the organization are visualized. Previous research suggests that the quality profile is difficult to change (Ahire, 1996; Johansson et al., 2010) and that successful implementation of quality management requires a radical change (Dobyns and Crawford-Mason, 1991; Munroe-Faure and MunroeFaure, 1992; Reger et al., 1994). Accordingly, a quality profile cannot simply be implemented on the basis of the existing management structures and systems. It may require the redesign of work, the redefinition of managerial roles, the redesign of organizational structures, the learning of new skills by employees and the reorientation of organizational goals (Grant et al., 1994).

\section{Digital Innovation}

Innovation can be viewed as the creation and adoption of an idea, a product or a technology that is new to the adopting unit (Gupta et al., 2007). Digital innovation refers to an innovation enabled by digital technologies that leads to the creation of new forms of digitalization (Yoo et al., 2009). Digital innovation is not merely a shift in technology of encoding diverse types of analogue information in digital forms, however, but also requires organizing new sociotechnical structures with digitized artefacts as well as changing artefacts themselves (Yoo et al., 2010). Digitalization has led to a constant reconfiguration of roles, relationships, work practices and identities among actors (Berente et al., 2007; Yoo et al., 2010) and can be a 
driver of organizational and business development (Swanson, 1994; Lyytinen and Rose, 2003).

Digital innovation can be separated into three types that are interrelated. The first type (Type 1) involves changes in system development processes, such as new development tools or programming teams. Type 2 consists of outcomes of development processes, i.e. services. This involves uses of IT to support the administrative core of the organization. Type 2 also deals with innovations in which the uses of IT affect either business functions or core processes of the organization, which is Type 3 (Swanson, 1994). These three types of innovations are mutually dependent, as an innovation in one type may lead to innovations in others. This co-dependency is created because digital innovation processes are simultaneously driven by both push and pull forces (Zmud, 1984). This illuminates the complexity of digital innovation and the impact on an organization.

\section{Empirical investigation}

An empirical study was carried out to explore the interrelationship of quality management and digital innovation at the Swedish Transport Administration (STA). Two data collection methods were used: a document study followed by an interview study. The document study comprised written material describing how the STA works with quality management. This was followed by the interview study, which involved quality management and IT professionals.

\section{Research Setting}

The STA is a newly established agency responsible for all modes of traffic: traffic on roads and railways, on the sea and in the air. The agency is also responsible for building, maintaining and operating all national roads and railways. The organization has 6500 employees in all of Sweden. It was established on April 1, 2010 after a special committee oversaw the efficiency of the Swedish transport agencies over a two-year period (2008-2009), reaching a conclusion that there were significant gains to be made by establishing a new agency for long-term planning of the whole transport system. The agency overtook all operations of the Swedish Road Administration and the Swedish Rail Administration as well as parts of the Swedish Maritime Administration, LFV (which operates air navigation services) and the Swedish Institute for Communication Analysis (the STA, 2011).

\section{Sample, Data Collection and Analysis}

Five quality management and three IT professionals at STA were interviewed, all highly conversant with their disciplines as well as having good knowledge about the organization. The interviews were semi-structured and revolved around the eight principles according to the ISO standard (ISO, 2000). The interview guide for the quality management professionals consisted of an introduction and a section about how each of the eight principles was applied by the professionals when working with quality management. The aim was to let the respondents talk freely about how the STA works according to these principles. For the IT professionals, the interview guide consisted of an introduction and questions about how the principles were applied in digital innovation. Based on the process of data reduction and coding, the interviews were then recorded and transcribed for further analysis (Miles and Huberman, 1994). The analysis was carried out using remarks in margins that identified key words. This enabled the data to be coded and organized to gain an understanding of (i) the 
characteristics of quality management and (ii) the characteristics of digital innovation according to these principles. After analysing all the interviews separately, the key words were summarized and compared. The last step of the analysis was to compare the application of the principles for quality management and the application of digital innovation, respectively, with the maturity model and associated evaluation grid proposed by Dale and Smith (1997). The evaluation grid gives guidance on how to judge the maturity. The guidance was therefore used in order to make the classification of the principles. Both authors made the analysis and, if different classifications were selected, the matter was discussed until consensus was reached.

The results were then presented to an independent group at the STA at a workshop during which a validation process was conducted. The respondents had no disagreement as to the presentation of the results and analysis.

\section{Results and analysis}

The following sections give the findings related to quality management and digital innovation. Our analysis of the interviews revealed various stages of development, see Table 1.

\section{The spectrum of principles for quality management}

In three out of eight principles, the approach to quality management is categorized as uncommitted. Those three principles are: leadership, factual approach to decision making and system approach to management. Two principles, customer focus and involvement of people, were categorized as initiators. The principle of process approach has the highest maturity (drifters) and two principles displayed the lowest maturity (unaware): continual improvement and mutually beneficial supplier relationships.

The STA has developed an overall process map and they map their processes in three out of four departments. The management team is not fully engaged in this work, however, which separates the process work somewhat from the organization. The culture of managing by departments at the STA is strong, and there is resistance towards establishing a process structure with appointed process managers. Further, the management team has a representative for quality management. However, this person has the role of CFO (Chief Financial Officer) as well which, as it appears, is an area that has a higher status in this organization than quality management. Hence, issues regarding economy are most often prioritized above quality. The routines for creating mutually beneficial relationships with suppliers are unclear, as are the routines for continuous improvement. The customer concept is also somewhat vague. Although the STA's marketing group regularly measures customer satisfaction, this information is not used to improve the processes. In addition, the STA keeps track of KPIs on a strategic level but there are no KPIs on a process level.

The quality management professionals focus on improving the process structure of the organization, which includes the creation of an overall process map and mapping the processes. The work with processes is conducted by a group of people from three out of four departments within the organization, which shows that the quality managers are striving to increase the involvement of employees with respect to development work.

This study has focused on the quality maturity in individual principles. In order to get an understanding of the STA's overall maturity, one of the respondents in this study, a quality management professional and also a trained examiner according to the SIQ model (the 
Swedish version of the European Foundation Quality Model), assessed the maturity as being up to about 75-100 points. Associated with this first stage of development is: a) a beginning of quality awareness; b) no integration or collaboration between different units within the organization; c) some systematic approaches are adopted in certain areas; d) the meaning of quality is not being considered; and e) some or no results can be demonstrated and the results have no connection with the approaches (SIQ, 2008).

\section{The spectrum of principles in digital innovation}

The analysis of principles in digital innovation shows that four out of eight principles are categorized as "uncommitted". Those are: customer focus, involvement of people, factual approach to decision making and system approach to management. Two principles are categorized as "initiators": process approach and leadership. Continual improvement and mutually beneficial supplier relationships are categorized as “drifters".

The area of digital innovation at the STA has had a low status over the years. However, during the recent reorganization, the management team now has a CIO (Chief Information Officer), which indicates that the status can be improved. Another principle that displayed a relatively higher stage of development in digital innovation is continuous improvement. The IT professionals demonstrate that they have special groups working on continuously improving the digital services in the organization.

The customer concept was somewhat unclear to the IT professionals. Some mentioned the organization and the personnel as the customers. Others mentioned the private operators that run the traffic as customers. The study showed that digital innovation is highly dependent on having a clear process perspective. Hence, digital innovation could benefit from focusing more on the processes. Also, the two principles of process approach and customer focus are closely related, as each process derives from the needs and expectations of a customer. By focusing more on processes could also improve the customer concept.

- Take in Table 1 here -

\section{A comparison of the principle of maturity between quality management and digital innovation}

Figure 1 displays the maturity level among the eight principles for the two concepts studied: quality management and digital innovation. These levels derive from the categorization made in Table 1.

- Take in Figure 1 here -

The analysis shows that, on an overall level, the majority of principles in both quality management and digital innovation are categorized as "uncommitted" or "initiators", which is the second and third stage of development according to the maturity grid by Dale and Smith (1997). The analysis of the maturity among the principles for quality management differs to 
some degree from that of digital innovation. Three principles display a higher level for quality management than for digital innovation: process approach, customer focus and involvement of people.

Further, Figure 1 displays two principles that are aligned (factual approach to decision making and system approach to management). The analysis shows that neither the quality management nor the IT professionals collect data in a systematic way in order to improve the processes. The decisions for digital innovation are made more randomly and are based on a project group and/or reference group's opinion rather than facts. Furthermore, each department is run independently from the others, with little collaboration. As a result of this, there is a lack of approaches for improving the system perspective.

Three principles show a higher stage of development for digital innovation: leadership, continuous improvement and mutually beneficial supplier relationships. The status of digital innovation at the STA seems higher than that of quality management. Hence, realizing digital innovation is most often given higher priority than quality management initiatives. This causes problems for the IT professionals since they are dependent on e.g. having a process structure, clear responsibility conditions and methods for measuring efficiency and effectiveness of digital innovations - all areas that delay the digital innovation process and could be viewed with quality management strategies. Further, the overall aim of quality management is continuous improvement. Interestingly, digital innovation displays a higher stage of development in this area. The reason for this is that the IT professionals have systematic routines for improving the digital innovations, which the quality management professionals lack in terms of improving the overall management system. A possible explanation for this is the greater complexity of developing routines for quality management, as it comprehends the whole management system, than for digital innovation. To conclude, digital innovation involves about $60 \%$ consultants, some that have been working for the STA for 10-20 years. As a result of this, the IT professionals have had time to develop beneficial relationships with these consultants, i.e. they are highly involved and have good knowledge of the organization and both its formal and informal procedures.

In summary, this study shows that the stages of development among the principles at the STA are relatively low, both for quality management and for digital innovation. However, the STA is a newly established agency that has undergone an organizational change during the past years. The two prior major agencies, the Road Administration and the Rail Administration, have been forced to integrate their way of working with quality management and digital innovation into one system and organization. Parallel to this process, the two organizations have gone through an efficiency program, cutting down 20 percent in personnel in all departments. The organizational change has had an effect on the stage of development in principles, since much of the work has required the two organizations to start from the beginning, e.g. identifying the processes all over again. The efficiency program has also taken focus from the internal development process, which has been treated as a separate project, i.e., the integration with the management system is minimal.

\section{Conclusions}

The purpose of this paper is to explore the maturity of quality management and digital innovation in an organisation. Furthermore, the purpose is to analyse the relationship between and learning opportunities of the two concepts based on that maturity. The analysis shows that, on an overall level, the majority of the principles studied concerning quality management and digital innovation are categorized as "uncommitted" or "initiators", which is the second 
and third stage of development. This indicates that the maturity level of the two concepts studied is rather low.

This study shows also that process orientation and involvement of people are two important principles for digital innovation. Specifically, realizing digital services requires a clear process structure. In this study we conclude that top management prioritized digital innovation above quality management, as digital innovation is seen as more concrete with clearer outcomes than quality management. However, digital services cannot be realized because of problems or uncertainties in the organization and its processes. This calls for working with quality management proactively and not, as shown in this study, reactively.

This study shows that the principle of continuous improvement displays the lowest maturity for quality management. This indicates that the STA as a whole is not focusing enough on development or innovation. This in turn hinders digital innovation. Although there is a lack of commitment from management, the quality management and IT professionals could work on improving their internal dialogue, discussing how they individually work with the principles and how they could collaborate in order to improve the overall management system and, in particular, digital innovation.

Certainly there are principles that have not been considered in ISO 9000 and in this study. The ISO standard has not incorporated concepts such as 'innovation', 'sustainability' or 'network', which both current practitioners and researchers put a great deal of emphasis on. Hence, quality management and ISO could benefit from reviewing the principles in order to keep up with recent research.

\section{Discussion}

This study shows that both the approaches to quality management and digital innovation can be reflected by the eight principles of ISO 9000. This can be explained by the general characteristic of the principles, but also by the interrelationship and co-dependency between quality management and digital innovation. Digital innovation affects the processes of the organization (Swanson, 1994), leads to the establishment of new horizontal links between workplaces (Ciborra and Lanzara, 1994) and requires a constant reshaping of roles, relationships, work practices and identities (Berente et al., 2007; Yoo et al., 2010). Further, digital innovation works both as a push and pull mechanism (Zmud, 1984) and is a driver of organizational and business development (Swanson, 1994; Lyytinen and Rose, 2003). Hence, these features of digital innovation have implications for quality management and, specifically, what principles, practices and techniques to address. Quality management and the overall management system can either inhibit or facilitate digital innovation. As this study shows that the maturity of quality management is rather low, it is likely that this inhibits digital innovation. Furthermore, both digital innovation and quality management are treated as separate functions in many organizations. Research shows however that they are both complex concepts that influence processes, work practices, roles and relationships (see e.g., Lyytinen and Rose, 2003; Dahlgaard et al., 1998) and should for that reason be integrated in the organization, from management to the operational levels, in order to provide value to the organization.

Instead of focusing on practices, such as Lean, ISO or Six Sigma, this study suggests that management should focus on the principles as they are present in all quality management programs and embedded in the organizational culture, including digital innovation (see also Johansson et al., 2010; Rönnbäck et al., 2011). Previous research suggests that service 
organizations, including the STA, should focus on the two principles of process approach and involvement of people (Rönnbäck and Witell, 2008). However, these two principles may also have a negative impact on customer orientation in low and medium mature organizations (Ettlie and Johnson, 1994). Customer focus displays low levels in early initiatives of quality management but increases for medium mature organizations (Johansson et al., 2010). This concurs with the results of this study, demonstrating that the STA has focused on the processes and displays a higher stage of development in this area compared to the other principles. In line with earlier studies (Ettlie and Johnson, 1994; Johansson et al., 2010), the customer concept is vague and not managed sufficiently.

As indicated here, the deployment of principles in an organization should be considered, specifically in digital innovation, as there is a relationship between digital innovation and organizational performance (Carlson and McNurlin, 1992; Benner and Tushman, 2002). Previous research suggests that quality management practices associated with process orientation may enhance exploitative innovation at the expense of exploratory innovation in information technology (Benner and Tushman, 2003). Benner and Tushman (2003) recommend managers to handle exploitation and exploration simultaneously by shielding exploratory innovation from quality management activities. At the STA, the quality management and IT professionals work with the principles differently and have reached different stages of development. This segregation of practicing principles may be positive in terms of being able to simultaneously handle exploitation and exploration.

\section{References}

Ahire, S.L. (1996). “TQM age versus quality: An empirical investigation”, Production and Inventory Management Journal, First quarter, pp. 18-23.

Benner, M.J. and Tushman, M.L (2002). "Process management and technological innovation: A longitudinal study of the photography and paint industries", Administrative Science Quarterly, Vol. 47 No. 4, pp. 676-706.

Benner, M.J. and Tushman, M.L (2003). "Exploitation, exploration and process management: The productivity dilemma revisited”, Academy of Management Review, Vol. 28 No. 2, pp. 238-256.

Berente, N., Srinivasan, N., Yoo, Y., Boland, R.J. and Lyytinen, K. (2007). ”Binate diversity and the rolling edge of design networks, International Conference on Information Systems, Montreal, Canada.

Bergman, B. and Klefsjö, B. (2010), Quality from customer needs to customer satisfaction, $4^{\text {th }}$ Edition, Studentlitteratur, Lund, Sweden.

Carlson, W. and McNurlin, B. (1992). "Basic principles for measuring IT value”, I/S Analyzer, Vol. 30 No. 10, pp. 1-16.

Ciborra, C.U. and Lanzara, G.F. (1994). "Formative contexts and information technology: Understanding the dynamics of innovation in organizations", Accounting, Management \& Information Technology, Vol. 4 No. 2, pp. 61-86.

Dahlgaard, J.J., Kristensen, K. and Kanji, G.K. (1994). The quality journey: A journey without an end, Carfax Publishing Company, Arbingdon. 
Dahlgaard, J.J., Kristensen, K. and Kanji, G.K. (1998). Fundamentals of Total Quality Management. London, Chapman \& Hall.

Dale, B.G. and Smith, M. (1997). "Spectrum of quality management implementation grid: development and use”, Managing Service Quality, Vol. 7 No. 6, pp. 307-311.

Dean, J.W. and Bowen, D.E. (1994). "Management theory and total quality: Improving research and practice through theory development", Academy of Management Review, Vol. 19 No. 3, pp. 392-418.

Dobyns, L. and Crawford-Mason, C. (1991). Quality or Else, Boston, MA: Houghton Mifflin.

Eriksson, H. and Hansson, J. (2002). “The impact of TQM on financial performance”. Measuring Business Excellence, Vol. 7 No 1, pp. 36-50.

Ettlie, J.E. and Johnson, M.D. (1994). "Product Development Benchmarking Versus Customer Focus in Applications of Quality Function Deployment”, Marketing Letters, Vol.5 No. 2, pp. 107-116.

Flynn, B.B., Schroeder, R.G. and Sakakibara, S. (1995). ”The impact of quality management practices on performance and competitive advantage”, Decision Sciences, Vol. 26 No. 5, pp. 659-691.

Garvin, D.A. (1988), Managing quality, The Free Press, New York, NY.

Grant, R.M., Shani, R. and Krishnan, R. (1994). “TQM's challenge to management theory and practice”, Sloan Management Review, Vol. 35 No. 2, pp. 25-35.

Gupta, A.K., Tesluk, P.E. and Taylor, M.S. (2007). "Innovation at and across multiple levels of analysis”, Organization Science, Vol. 18 No. 6, pp. 885-897.

Hatch, M. J. (2000). Organisationsteori. Moderna, symboliska och postmoderna perspektiv. Lund, Studentlitteratur (In Swedish).

Hendricks, K.B. and Singhal, V.R (1995). "The impact of capacity expansion in the market value of the firm”, Journal of Operations Management, Vol. 12 No. 3, pp. 259-272.

Hendricks, K.B. and Singhal, V.R (1996). "Quality awards and the market value of the firm: An empirical investigation”, Management Science, Vol. 42 No. 3, pp. 415-436.

Hendricks, K.B. and Singhal, V.R. (1997). "Does implementing an effective TQM program actually improve operating performance? Empirical evidence from firms that have won quality awards”, Management Science, Vol. 43 No 9, pp. 1258-1274.

Hendricks, K.B. and Singhal, V.R. (2001a). "The long-run stock price performance of firms with effective TQM programs”, Management Science, Vol. 47 No. 3, pp. 359-368.

Hendricks, K.B. and Singhal, V.R. (2001b). "Firm characteristics, total quality management, and financial performance”, Journal of Operations Management, Vol. 19 No. 3, p. 269-285.

ISO. (2000). Quality management systems - requirements (ISO 9001:2000), SSEN ISO 9001:2000, 31 pages, SIS. 
ISO (2011). International organization for standardization. Available at: http://www.iso.org/ (Dec 7, 2011).

Johansson, E., Witell, L. and Elg, M. (2010). "Evolvement of quality profiles in Swedish service organizations", Published in the proceedings of the $13^{\text {th }}$ Quality Management and Organizational Development (QMOD) Conference, Cottbus, Brandenburg, Germany.

Lascelles, D.M. and Dale, B.G. (1991). "Levelling out the future”, Total Quality Management, Vol. 2 No. 6, pp. 325-330.

Lyytinen, K. and Rose, G.M. (2003). "The disruptive nature of information technology innovations: The case of internet computing in systems development organizations”, MIS Quarterly, Vol. 27 No. 4, pp. 557-595.

Miles, M.B. and Huberman, A.M. (1994). Qualitative data analysis, $2^{\text {nd }}$ Edition, Sage, Thousand Oaks, California.

Morgan, G. (1997). Images of organization, $2^{\text {nd }}$ Edition. Thousand Oaks, California, Sage Publications.

Munroe-Faure, L. and Munroe-Faure, M. (1992). Implementing total quality management, Pitman, London.

Myers, B.L., Kappelman, L.A. and Prybutok, V.R. (1997). “A comprehensive model for assessing the quality and productivity of the information systems function: Toward a theory for information systems assessment”, Information Resources Management Journal, Vol. 10 No. 1, pp. 6-26.

Reeves, C. and Bednar, D. (1994). "Defining quality: Alternatives and implications", Academy of Management Review, Vol. 19 No. 3, pp. 419-445.

Reger, R.K., Gustafsson, L.T., Demarie, S.M. and Mulland, J.V. (1994). "Reframing the organization: why implementing total quality is easier said than done", Academy of Management Review, Vol. 19 No. 3, pp. 565-584.

Rönnbäck, Å. and Witell, L. (2008). “A review of empirical investigations comparing quality initiatives in manufacturing and service organizations”, Managing Service Quality, Vol. 18 No. 6, pp. 577-593.

Rönnbäck, Å, Johansson, E. and Witell, L. (2011). ”Why changing a quality profile is easier said than done", Published in the Proceedings of the $12^{\text {th }}$ International Research Symposium on Service Excellence in Management, QUIS, Ithaca, NY, 2011.

Schein, E.H. (1992). Organisational culture and leadership, $2^{\text {nd }}$ Edition. San Francisco, Jossey-Bass Publishers.

SIQ (2008), The SIQ model for performance excellence, Swedish Institute for Quality (SIQ), Gothenburg.

Slappendel, C. (1996). "Perspectives on innovation in organizations", Organization Studies, Vol. 17 No. 1, pp. 107-129. 
Swanson, E.B. (1994). "Information systems innovation among organizations”, Management Science, Vol. 40 No. 9, pp. 1069-1088.

The STA. (2011). The Swedish Transport Administration. Available at: http://www.trafikverket.se (October 18, 2011).

Tuomi, I. (2006). Networks of innovation: Change and meaning in the age of the Internet, Oxford University Press, Oxford.

Van Dyke, T.P., Prybutok, V.R. and Kappelman, L.A. (1999). "Measure to assess the quality of information systems services”, Decision Sciences, Vol. 30 No. 3, pp. 877-891.

Yoo, Y., Lyytinen, K. and Boland, R. J. (2009). ”Innovation in the digital era: Digitization and four classes of innovation networks", Working Paper, Temple University.

Yoo, Y., Lyytinen, K., Boland, R., Berente, N., Gaskin, J., Schutz, D. and Srinivasan, N. (2010). "The next wave of digital innovation: Opportunities and challenges, A report of a research workshop on Digital challenges in innovation research”.

Zmud, R. (1984). "An examination of push-pull theory applied to process innovation in knowledge work”, Management Science, Vol. 30 No. 6, pp. 727-738. 


\section{TABLES}

Table 1. Results

\begin{tabular}{|c|c|c|}
\hline $\begin{array}{l}\text { Concepts } \\
\text { Principles } \\
\end{array}$ & The characteristics of quality management & The characteristics of digital innovation \\
\hline $\begin{array}{l}\text { Process } \\
\text { approach }\end{array}$ & $\begin{array}{l}\text { - The STA is mapping the processes. } \\
\text { - Not organized or divided responsibility according to the processes. } \\
\text { - No process owner responsible for improving the processes. } \\
\text { - Process mapping is done in } 3 \text { out of } 4 \text { departments. } \\
\text { - A project group has been assigned to structure the work with the } \\
\text { management system, specifically the process work. } \\
\text { - Process groups which improved communications were established } \\
\text { 4. Drifters }\end{array}$ & $\begin{array}{l}\text { - Digital services are developed according to the processes, which } \\
\text { makes it necessary to understand the processes and have them } \\
\text { mapped. } \\
\text { - There is frustration among the IT professionals since the processes are } \\
\text { not mapped, which makes it difficult and time-consuming to develop } \\
\text { digital services. } \\
\text { - There are no process owners, which causes problems as no one takes } \\
\text { responsibility cross-functionally. } \\
\text { 3.Initiators }\end{array}$ \\
\hline Categorization & $\begin{array}{l}\text { - The customer concept is somewhat vague. } \\
\text { - Since the customer has an unclear role in the organization, this means that the } \\
\text { principle customer focus is not being managed sufficiently. } \\
\text { - The STA has some approaches, such as regularly measuring customer } \\
\text { satisfaction, but it is unclear how this information is used in order to improve } \\
\text { the processes. } \\
\text { 3. Initiators }\end{array}$ & $\begin{array}{l}\text { - Most respondents among the IT professionals identified the STA as } \\
\text { the customer, since they perceive it such that they develop digital } \\
\text { services to support the STA's processes. Some of the respondents } \\
\text { mentioned the operators as customers and some also included the } \\
\text { passengers as the customer. } \\
\text { - The customer concept is undergoing a transformation due to the re- } \\
\text { establishment of the IT organization with an altered mission. } \\
\text { 2. Uncommitted }\end{array}$ \\
\hline Leadership & $\begin{array}{l}\text { - Systematic improvement work is not a prioritized area at the STA. } \\
\text { - Management is not taking full responsibility of the management system, as } \\
\text { they have assigned a project group and delegated this issue. Hence, this } \\
\text { makes it difficult to integrate quality management as a part of the } \\
\text { organizational culture. } \\
\text { - The STA started to work with processes in the late '90s, but as management } \\
\text { did not perceive it as something that brings value to the organization the } \\
\text { process work was abandoned. } \\
\text { - One of the reasons for the failure with process approach was the strong } \\
\text { culture of managing by departments. }\end{array}$ & $\begin{array}{l}\text { - Digital innovation has a tradition of not being a prioritized area or } \\
\text { seen as a management issue. However, very recently, the management } \\
\text { group has incorporated a CIO. } \\
\text { - Decisions regarding digital innovation are most often made by people } \\
\text { in the organization who do not have the authority to prioritize this } \\
\text { work among other issues. They have also difficulties assembling } \\
\text { enough people to realize the digital services. } \\
\text { - About } 60 \% \text { of the IT professionals at the STA are consultants, which } \\
\text { causes problems as they may often lack formal authority. }\end{array}$ \\
\hline Categorization & & 3. Initiators \\
\hline
\end{tabular}




\begin{tabular}{|c|c|c|}
\hline $\begin{array}{l}\text { Involvement of } \\
\text { people }\end{array}$ & $\begin{array}{l}\text { - The process mapping work involves some employees, about } 10-15 \text { people in } \\
\text { the largest department, and all process work is done within the individual } \\
\text { departments and not cross-functionally. } \\
\text { - The project group that has been assigned to oversee the management system } \\
\text { is an independent group, but includes the quality managers from the } 4 \\
\text { departments. } \\
\text { 3. Initiators }\end{array}$ & $\begin{array}{l}\text { - More people need to be involved in realizing digital services. } \\
\text { - Decisions regarding digital services are made by people in the } \\
\text { organization who do not have authority to prioritize the digital service } \\
\text { or to engage people in the process. } \\
\text { - Many of the digital innovation projects are run by consultants without } \\
\text { formal authority in the organization. } \\
\text { 2. Uncommitted }\end{array}$ \\
\hline $\begin{array}{l}\text { Factual } \\
\text { approach to } \\
\text { decision making }\end{array}$ & $\begin{array}{l}\text { - The marketing group conducts measurements of customer satisfaction } \\
\text { regularly. It is however unclear how these data are used to make decisions } \\
\text { regarding the development of the management system. It is not being used } \\
\text { to improve the processes. } \\
\text { - Management is following up some KPIs on a strategic level. }\end{array}$ & $\begin{array}{l}\text { - The departments are managed hierarchically and separately from one } \\
\text { another. Hence, there is very little collaboration with respect to digital } \\
\text { innovation. } \\
\text { - The departments most often develop their own digital services before } \\
\text { making sure that another department has not created an equal system. } \\
\text { - They do not collect data systematically before making decisions with } \\
\text { respect to digital innovation. }\end{array}$ \\
\hline Categorisation & 2. Uncommitted & 2. Uncommitted \\
\hline $\begin{array}{l}\text { Continual } \\
\text { improvement } \\
\text { Categorization }\end{array}$ & $\begin{array}{l}\text { - The routines for continuous improvement are unclear. } \\
\text { 1. Unaware }\end{array}$ & $\begin{array}{l}\text { - IT professionals have special groups that work on continuously } \\
\text { improving the various digital services. } \\
\text { 4. Drifters }\end{array}$ \\
\hline $\begin{array}{l}\text { Mutually } \\
\text { beneficial } \\
\text { supplier } \\
\text { relationships } \\
\text { Categorization }\end{array}$ & $\begin{array}{l}\text { - The process of how the STA procures suppliers is somewhat unclear. } \\
\text { - The customer perspective is not included in the procurement process. }\end{array}$ & $\begin{array}{l}\text { - The process for procuring IT consultants is somewhat unclear. } \\
\text { - About } 60 \% \text { of the IT professionals are consultants and many of them } \\
\text { have worked in the organization for } 10-20 \text { years, which makes them } \\
\text { part of the organizational culture but without having formal authority. } \\
\text { 4. Drifters }\end{array}$ \\
\hline $\begin{array}{l}\text { System } \\
\text { approach to } \\
\text { management }\end{array}$ & $\begin{array}{l}\text { - The STA works hierarchically according to the departments, not according } \\
\text { to the processes. } \\
\text { - The STA does not take a system approach. There are no process owners that } \\
\text { are responsible for the cross-functional processes. }\end{array}$ & $\begin{array}{l}\text { - The STA works according to the } 4 \text { departments, which make their } \\
\text { own decisions when it comes to digital innovation. } \\
\text { - The departments develop their own digital services before checking } \\
\text { whether another department has developed an equal system. } \\
\text { - The digital innovation process is being run hierarchically without a } \\
\text { system perspective. }\end{array}$ \\
\hline Categorization & 2.Uncommitted & 2. Uncommitted \\
\hline
\end{tabular}




\section{FIGURES}

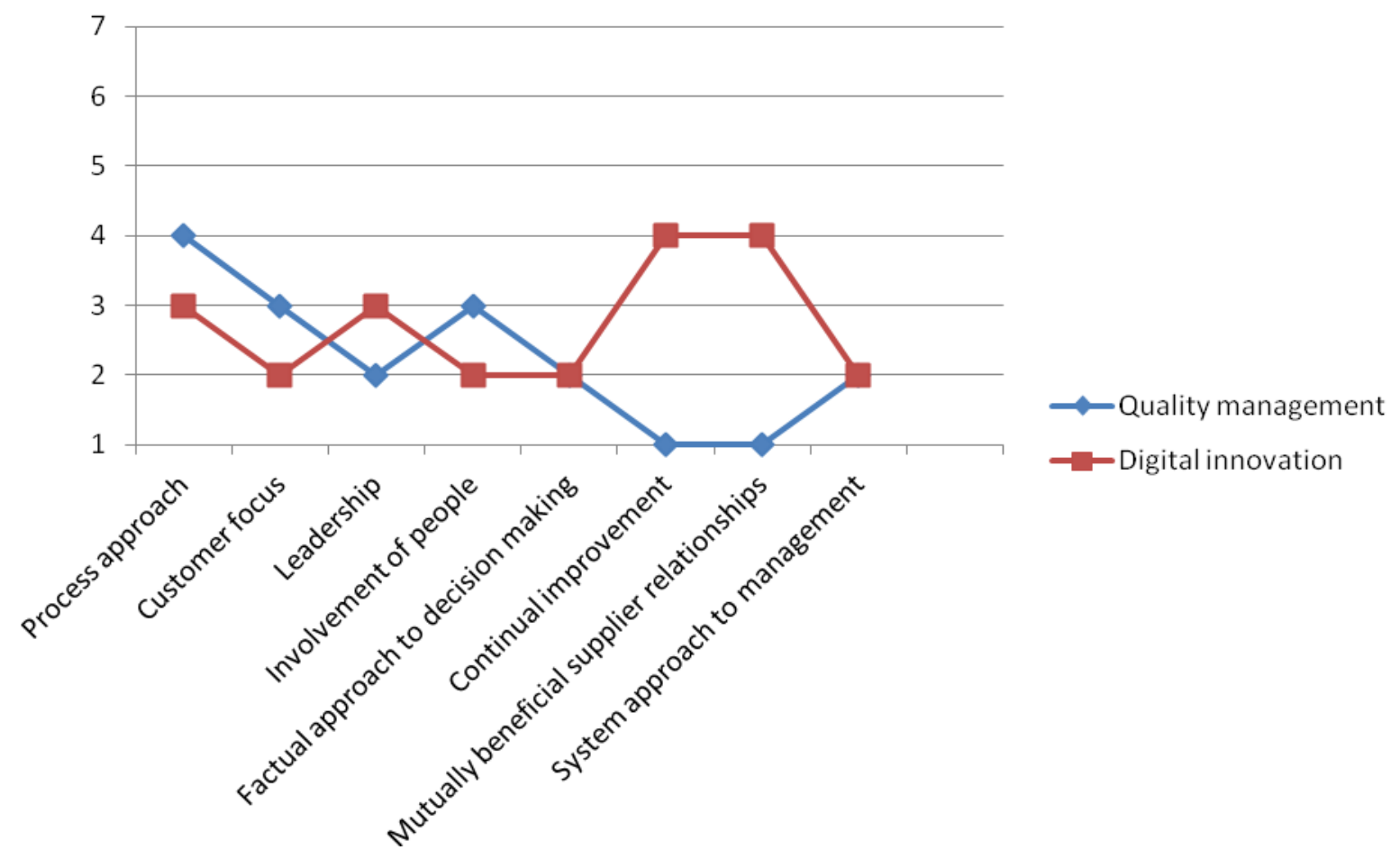

Figure 1 The spectrum of principles in the two studied domains based on the evaluation grid by Dale and Smith (1997). 